\title{
Methanol extract of Solanum violaceum root possesess antiobesity, hypolipidemic, thrombolytic and membrane stabilizing activity
}

\author{
Sayed Koushik AHAMED ${ }^{1,2}$ Md. Imdadul Huque KHAN ${ }^{1}$, Md. Mustahsan BILLAH ${ }^{1}$, Mohammad Salim HOSSAIN ${ }^{\text {* }}$ \\ Department of Pharmacy, Noakhali Science and Technology University, Noakhali-3814, Bangladesh \\ 2 Present address: Department of Pharmacy, Comilla University, Comilla, Bangladesh
}

\begin{abstract}
Roots of Solanum violaceum (S. violaceum) is used traditionally in different therapeutic applications in Bangladesh. Root extract of $S$. violaceum was investigated for total phenolic content (TPC), antiobesity, anti-hyperlipidemic, membrane stability and thrombolytic activity. Total phenolic content (TPC) was determined using folin-ciocalteu method. High fat diet induced obese mice were used for anti obesity and antihyperlipidemic test. Body weight gain, blood total cholesterol, triglyceride level were analyzed. Thrombolytic and membrane stability activity were evaluated by using human erythrocytes. Total phenolic content in root extract of $S$. violaceum was calculated as $51.26 \mathrm{mg}$ gallic acid equivalent GAE/g of dry weight. The extractive supplementation with dose of $200 \mathrm{mg} /$ $\mathrm{kg}$ and $400 \mathrm{mg} / \mathrm{kg}$ were capable of lowering the level of triglyceride and total cholesterol significantly $(\mathrm{p}<0.05)$ in high fat diet (HFD) induced obese mice in a dose dependent manner. As a membrane stabilizing agent, crude extract was able to inhibit the erythrocyte heamolysis significantly $(\mathrm{p}<0.05)$ with a value of $28.02 \pm 5.09 \%$ and $32.97 \pm 4.12 \%$ respectively for heat and hypotonic solution induced condition. Moreover, $21.56 \pm 2.62 \%$ of clot lysis was exhibited by the extract for its thrombolytic activity. The root of S. violaceum justifies its potential as anti obese agent. Further research is recommended to find out the active metabolites from this source.
\end{abstract}

KEYWORDS: Obesity; Antihyperlipidemia; Thrombolysis; Inflammation; S. violaceum

\section{INTRODUCTION}

According to world health organization (WHO) almost $80 \%$ of the world population presently uses herbal medicine for their primary health care (1). During the last few decades, advances in the identification of new bioactive compounds from plants have renewed the popularity of herbal medicines (2). In fact, due to belief that 'Green Medicine' is safe, effective and reliable than synthetic drugs, many pharmaceutical companies are interest in plant derived drugs (3). Various pharmaceuticals have been started in preparing various form of medicine using chemical constituents such as the alkaloids, glycosides, flavonoids, tannins, resins and volatile oils obtained as secondary metabolites from medicinal plants (4).

Now a days the prevelence of obesity is dramticaly increased around the world. Obesity is considered as a major risk factor for mortality and morbidity associated with others health problems (5). According to WHO reports high cholesterol level in blood is responsible for approximately $56 \%$ of cardiovascular disease worldwide and causes 4.4 million deaths each year and hyperlipidemia identified by hypercholesterolemia is the most common cause for this disease. Over the past 30 years, few obesity-treatment drugs have been developed or approved

Received: 14.05.2017/ Accepted: 03.10.2017

Corresponding Author: Mohammad Salim Hossain

E-mail: Email: pharmasalim@yahoo.com

Phone: +8801711200410

ORCID No: 0000-0002-5710-1115 for which only two drugs are currently available (6). To fight against such type of diseases discovery of new bioactive metabolites is essential. Hence, screening medicinal plants for promising bioactive metabolites to discover novel drug candidate is a necessity (7).

S. Violaceum belongs to Solanaceae family which is traditionaly used for medicinal treatments. Leaf juice is used to stop vomiting and the seeds are used in the treatment of toothache (8). Fruits are considered anthelmintic, laxative and digestive; useful in pruritus, leucoderma and asthma (9). Traditionally the root is used in bronchitis and asthma. It is also used as a digestive, carminative and astringent to the bowels, fever, etc.

In this present study, we have investigated the root of $S$. violaceum and gone through different biological tests to asure the presence of bioactive metabolites which will lead to find a bioacive novel compound precursor of novel drug.

How to cite this article: Ahamed SK, Khan MIH, Billah MM, Hossain MS. Methanol extract of Solanum violaceum root possesess antiobesity, hypolipidemic, thrombolytic and membrane stabilizing activity. Marmara Pharm J. 2018; 22 (1): 96-102 


\section{RESULTS}

\subsection{Total phenolic content in methanolic extract of root of}

\section{S. violaceum}

Methanolic crude extract of S. violaceum root was subjected for the determination of total phenolic content TPC. It was calculated as gallic acid equivalent (GAE) in the extractive and the value was $51.26 \pm 0.13 \mathrm{mg}$ per gm dry weight.

\subsection{Effect of methanolic extract of root of S. violaceum on body weight in high fat diet induced obesity}

There was no momentous difference in the body weight among the groups of animals at the beginning of the study. Mice fed on high fat diet (HFD) started to gain weight after twelve days of feeding and continued till the end of experimental period $(\mathrm{p}<0.05)$ whereas, when extract supplemented with a doses of $200 \mathrm{mg} / \mathrm{kg}$ and $400 \mathrm{mg} / \mathrm{kg}$ to HFD, caused the significant $(\mathrm{p}<0.05)$ decrease in body weight. Data are presented in Figure 1. Weight gain was preferentially less in the groups supplemented with $400 \mathrm{mg} /$ $\mathrm{kg}$ than that with $200 \mathrm{mg} / \mathrm{kg}$. No remarkable differences in food intake among the groups were noticed.

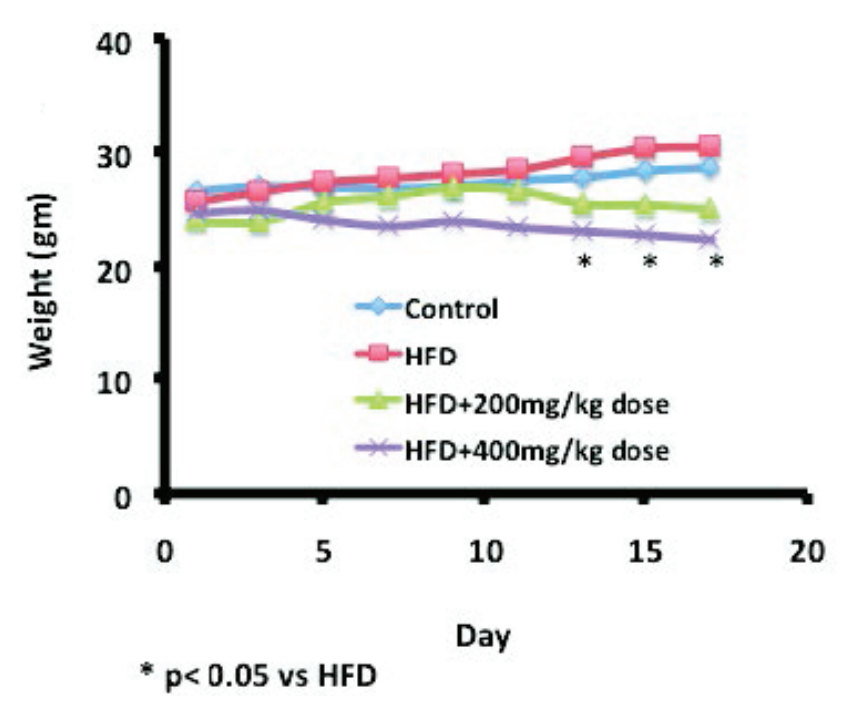

Figure 1. Changes of body weight of different groups

\subsection{Effect of methanolic extract of root of S. violaceum on hyperlipidemia}

Along with the weight gain, HFD group shows significantly elevated level of triglyceride and total cholesterol than that of controlled group as predicted $(\mathrm{p}<0.05)$. However, treatment with extractive, reversed the hyperlipidemic effect governed by high fat diet $(\mathrm{p}<0.05)$. Lowering of hyperlipidemia was observed in a dose dependent manner (Figure 2, 3).

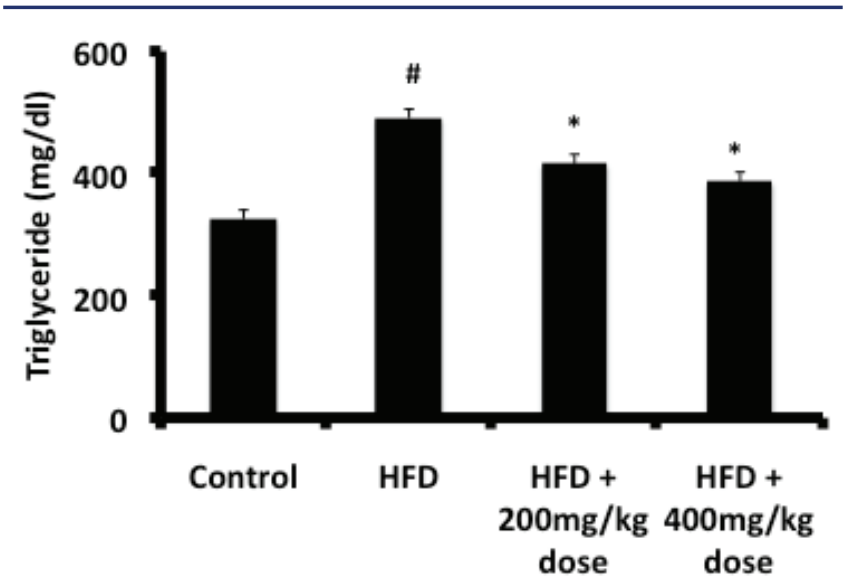

Figure 2. Effect of root of $S$. violaceum on Triglyceride level $\# \mathrm{p}<0.05$ vs control

${ }^{*} \mathrm{p}<0.05$ vs HFD

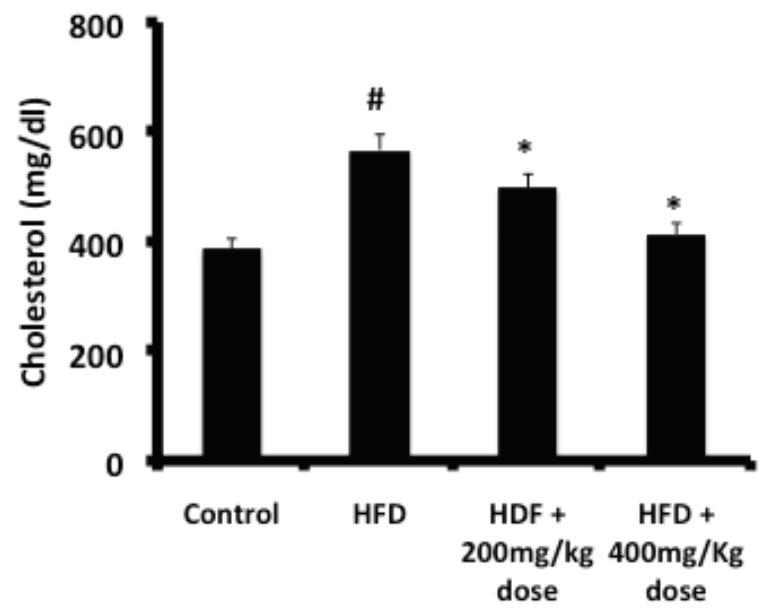

Figure 3. Effect of root of $S$. violaceum on Cholesterol level $\# \mathrm{p}<0.05$ vs control

${ }^{*} \mathrm{p}<0.05$ vs HFD

2.4 Thrombolytic activity of methanolic extract of root of S. violaceum

Crude extract was applied to evaluate the thrombolytic activity. The extractive was able to lysis the clot with a value of $21.56 \%$ whereas the streptokinase causes about $59.7 \%$ clot lysis (Table 1). Although clot lysis activity of the extractive was less than that of standard used but significant degree of clot lysis was observed by the extractive while compared with the control $(\mathrm{p}<0.05)$. 
Table 1. Thrombolytic activity in terms of $\%$ of clot lyses by standard and S.violaceum crude extract

\begin{tabular}{|c|c|}
\hline Test samples & $\begin{array}{c}\text { \% clot lyses } \\
\text { (Thrombolytic activity) }\end{array}$ \\
\hline Streptokinase (Standard) & $59.7^{*}$ \\
\hline Methanol extract & $21.56^{*}$ \\
\hline control & 3.06 \\
\hline
\end{tabular}

${ }^{*} \mathrm{P}<0.05$ vs control

\subsection{Membrane stabilizing activity of methanolic extract of root of S. violaceum}

Membrane stabilizing activity as function of antiinflammatory response by the extractive was documented using human erythrocyte as a model. Haemolysis of erythrocyte was induced by either hypotonic solution or heat. Inhibition of haemolysis by the extractive was calculated and the data was presented in Table 2. Methalonic extract showed significant $(\mathrm{p}<0.05)$ inhibition of heamolysis in both the cases compared with control. Extractive was more effective to inhibit the hypotonic solution induced heamolysis than that caused by heat.

Table 2. Erythrocyte membrane stabilization in terms of \% inhibition of haemolysis (in hypotonic solution - and heatinduced conditions) by standard and S.violaceum crude extract

\begin{tabular}{|c|c|c|}
\hline \multirow{2}{*}{ Test samples } & \multicolumn{2}{|c|}{$\begin{array}{c}\text { \% Inhibition of Haemolysis } \\
\text { (Erythrocyte membrane stabilization) }\end{array}$} \\
\cline { 2 - 3 } & $\begin{array}{c}\text { Hypotonic solution } \\
(50 \mathrm{mM}) \text { induced }\end{array}$ & Heat-induced \\
\hline $\begin{array}{c}\text { Acetyl salicylic acid } \\
\text { (Standard) }\end{array}$ & $70.99^{*}$ & $75.81^{*}$ \\
\hline Methanol extract & $25.7^{*}$ & $28.02^{*}$ \\
\hline
\end{tabular}

${ }^{*} \mathrm{P}<0.05$ vs control

\section{DISCUSSION}

Plants from Solanaceae family have been documented for anti-diabetic, anti-ulcerogenic properties $(10,11)$. Here methanolic extract of roots of $S$. violaceum, a plant from Sonalaceae has been studied for the antiobesity, antihyperlipidemic, and other related activities. Although lethal dose of this test-extract was not determined in this experiment, but we did not observe any death of experimental animal with the doses applied for the study.

Obesity is a major risk factor for mortality and morbidity associated with other health problems (5). HFD induced model for obesity has well been studied previously as it mimic the basic adipogenic episodes in human (12). Body weight gain is an indicator for the development of obesity, leading to other metabolic disorders (13). In this study, we found the significant weight gain by the mice feed with HFD, compared with normal diet feed group, thus it confirms the obese status. Treatment of HFD mice with extract of $S$. violaceum at $200 \mathrm{mg} / \mathrm{kg}$ and $400 \mathrm{mg} / \mathrm{kg}$ significantly reduced the body weight when compared with HFD mice. This result suggests that the test-extract supplementation has remarkable capability to prevent body weight gain. We assumed this loss of weight gain might be associated with inhibition of food intake by the treated mice but interestingly we did not observed any remarkable changes in the rate of food intake by the animals even in any group.

Furthermore, hyperlipidemia, characterized by hypertriglycemia and hypercholesterolemia, is another parameter to study the pathogenesis of obesity. In this study, HFD mice showed a considerable elevation in triglyceride and total cholesterol compared with normal diet, while the treatment with extract in HFD mice reduced the triglyceride and total cholesterol level significantly, confirming further, the ability of the extract to ameliorate the development of obesity and other related complications. The antihyperlipidemic activity of the crude extract was dose dependent, i.e dose at $400 \mathrm{mg} / \mathrm{kg}$ was more effective than $200 \mathrm{mg} / \mathrm{kg}$ to reduce the accumulation of triglycerides and total cholesterol. It is evidenced that, drug like simvastatin, showing the ability to lower the cholesterol level (14) are used to treat obesity mediated cardiac complication. Although it is not clear, how does this extract lower the lipid accumulation in HFD mice but several lines of evidence has been reported that the natural products may decrease the lipid absorption by inhibiting the activity of pancreatic lipase (15). Orlistat an antiobese drug is a derivative of naturally occurring lipase inhibitor (16). Furthermore, polyphenols present in plant extract shows a significant inhibitory activity against pancreatic lipase (17-20). Moreover, polyphenols are also associated with apoptosis of adipocytes $(21,22)$ and inhibit the differentiation of 3T3-L1 cells by arresting the cell cycle at G1 phase (23). The phenolic content present in this extract may play a role in antiobese functions of the plant extract either by any mechanism stated above. Moreover, besides phenolic compounds, S. violaceum contains many other phytochemicals like alkaloids, glycosides and others (24), these bioactive metabolites might also contributed to the attenuation of HFD induced obesity by regulating the synthesis and metabolic pathway of fatty acid and cholesterol. To confirm the exact mechanism further investigation is warrant.

Obesity is also considered as risk factor for the development of arterial thrombosis and venous thromboembolism (25). In developed countries, thromboembolic disorders such as pulmonary emboli, deep vein thrombosis, heart attacks, and strokes are the main causes of mortality and morbidity (26). Again, the first generation thrombolytic agents such as streptokinase, urokinase show relatively weak substrate specificity and can cause side effects of systemic 
fibrinolysis and associated bleeding complications (27). Hence, to develop improved recombinant variants of these drugs, attempts are underway (28). Considering theses, we studied the thrombolytic activity of the crude extract. Crude methanolic extract of $S$. violaceum showed mild thrombolytic activity compared with streptokinase. This finding may drive the scientist to consider the $S$. violaceum root as a target to develop the drug at the intersection of obesity and thrombolysis.

Inflammation is a complex biological response of vascular tissues to harmful stimuli. Inflammatory mediators like prostaglandin, is associated with the adipogenesis procedure and treatment with COX inhibitors significantly reduced the fat accumulation in 3T3-L1 cells with attenuated synthesis of prostaglandin (29). Taking this in mind, we examined the anti-inflammatory potentials of the crude extract by assessing the membrane stabilizing activity using acetyl salicylic acid as a positive control. Membrane stabilization is well studied as a mechanism of anti-inflammatory response (30). Our data revealed that the methanolic extract of $S$. violaceum has significant inhibition capacity of erythrocyte haemolysis in hypotonic solution and heat-induced condition. As erythrocyte cell membrane is similar to lysosomal membrane components, it is extrapolated that the drugs which stabilizes erythrocyte membrane, also can stabilizes lysosomal membrane (31) and thus interfere with the release and or action of mediators responsible for inflammation like histamine, serotonin, prostaglandins, etc. (30). It is reported that the extract from plants of Solanaceae family poses the membrane stabilizing and anti-inflammatory activities (32). Thus, our test-extract may be a potent inhibitor to release the inflammatory mediators and attenuates the inflammatory responses in obese condition.

\section{CONCLUSION}

In conclusion, despite of the unknown mechanism, our data suggests that, root extract of $S$. violaceum poses a good potentiality to attenuate the obesity and obesity related complications. Thus finding out the bioactive metabolites from this source may quench the thirst of new drugs for the treatment of obesity and related disorders.

\section{MATERIALS AND METHODS}

\subsection{General experimental procedure}

Rotary evaporator (Büchi 011, USA) was used to concentrate extract. Cholesterol and Triglycerides liquicolor (Origin $\mathrm{GmbH}$, Germany, Centonic Germany), Colorimeter (AP101, APEL, Japan), Glucometer (Model No - Sensocard, Hungary) and UV-spectrophotometer (Shimatzu, Japan) were used for different experiments. All chemicals used for experiment were of analytical grade.

\subsection{Plant material}

The Root of S.violaceum was collected from Sonapur, Noakhali, Bangladesh in March, 2013. The plant sample was identified and authenticated by Bangladesh National Herbarium, Mirpur, Dhaka (Accession number: 37751).

\subsection{Preparation of extracts}

The washed and shade dried roots of the plants were ground into fine poweder by blending machine. The crude powdered materials $(800 \mathrm{mg}$ ) were cold extracted and macerated with methanol at room temperature for 7 days. The methanol extract thus obtained was filtrated and evaporated to drynesss with a rotary evaporator to get semi-solid extract.

\subsection{Experimental Animals}

Twenty healthy Swiss Albino mice (Sex: Male) were collected from Jahangir Nagar University, Dhaka, Bangladesh and were kept in dry polypropylene cages with 12 hours light dark cycle at $25 \pm 2^{\circ} \mathrm{C}$ and $55 \pm 10 \%$ relative humidity. Throughout the whole experiments, all mice were given human care according to the criteria mentioned in the 'Guide for the Care and Use of Laboratory Animals', which was prepared by the National Academy of Sciences and published by the National Institute of Health (US) and the permission was taken from the concern institute.

\subsection{Total phenolic content}

Total phenolic content of root of S. violaceum was estimated as described by Singleton and Rossi (33) and modified by $\mathrm{Kim}$ et al (34). Briefly, $0.5 \mathrm{ml}$ of extract $(1.0 \mathrm{mg} / \mathrm{ml}$, triplicates) were introduced into test tubes; $2.5 \mathrm{ml}$ of FolinCiocalteu's reagent and $2.0 \mathrm{ml}$ of sodium carbonate $(7.5 \%$ $\mathrm{w} / \mathrm{v}$ ) were added. The tubes were mixed and allowed to stand for $30 \mathrm{~min}$. Absorption at $760 \mathrm{~nm}$ was measured (Systronics UV-vis spectrophotometer). The total phenolic content was expressed as gallic acid equivalents (GAE) in milligrams per gram dry material.

\subsection{Anti obesity test}

Extractive of the S. violaceum was dispersed in $0.9 \%$ saline water and 1-2 drops of tween 80 was added to facilitate the administration of extractives orally.

The Swiss Albino mice were divided into four separate groups of 5 mice in each. Group 1 was considered as control group and was administrated normal diet, Group 2 was considered as obese and was administered high fat diet (regular diet supplemented with 20\% fat). Group-3 and 4 both were administrated high fat diet along with $200 \mathrm{mg} / \mathrm{kg} /$ day of extract and $400 \mathrm{mg} / \mathrm{kg} /$ day of extract, respectively. 
During the expermental period, mice weight was recorded in every two days. After 18 days the animals were killed by decapitation, and blood was collected for analysis.

\subsection{Hypolipidemic activity}

The total serum cholesterol was estimated by enzymatic end point (CHOD-PAP) method (35) whereas triglyceride was estimated by enzymatic colorimetric GPO-PAP method (36) using commercial analytical kit as per manufacturer instructions. Cholesterol kit (CAT \# CH 200, Randox Laboratories, UK) Triglyceride kit (CAT \# CS 611, Crescent Diagnostics, Soudia Arabia) respectively.

\subsection{Thrombolytic activity}

In vitro thrombolytic activity was evaluated by the method developed by Prasad et al. (37) by using Lyophilized Altepase (Streptokinase) as a positive control and distilled water as a negative control, respectively. Method described briefly as, venous blood $(5 \mathrm{ml})$ was drawn from healthy volunteers, and transferred in pre-weighed sterile micro tubes to form clots and incubated at $37^{\circ} \mathrm{C}$ for 45 minutes. After the clot formation, the serum was removed without disturbing the clot and tubes were re-weighted to get the clot weight (Clot weight $=$ weight of the tube containing clot - weight of the tube alone). Crude methanolic extractive, streptokinase (100 $\mathrm{ml}$ ), when applicable, was added to the tubes containing the clot and the tubes were incubated for 90 minutes at $37^{\circ} \mathrm{C}$ to observed the clot lysis. After the incubation, released fluid was removed and the tubes were weighted again to estimate the difference in weight after clot disruption. Differences obtained in weight taken before and after clot lysis was expressed as percentage of clot lysis as below

$\%$ of clot lysis $=($ Weight of released clot/clot weight $)$ X 100

\subsection{Membrane stabilizing activity}

The membrane stabilizing activity using in hypotonic and heat-induced conditions was determined following the method developed by Omale et al. (31) with slight modification. Briefly described as

Erythrocyte suspension: Whole blood from male human volunteers was collected under standard condition. EDTA was used to prevent clotting. The blood was washed three times with isotonic solution $(154 \mathrm{mM} \mathrm{NaCl}$ in $10 \mathrm{mM}$ sodium phosphate buffer, $\mathrm{pH}$ 7.4) through centrifugation for $10 \mathrm{~min}$ at $3000 \mathrm{rpm}$. Thus the suspension finally collected was considered as stock erythrocyte (RBC) suspension.

Hypotonic solution induced haemolysis: Extractive (1.0 $\mathrm{mg} / \mathrm{ml})$ or acetyl salicylic acid $(0.1 \mathrm{mg} / \mathrm{ml})$ was added to the erythrocyte (RBC) suspension $(0.5 \mathrm{ml})$ in $5 \mathrm{ml}$ hypotonic solution $(50 \mathrm{mM} \mathrm{NaCl}$ in $10 \mathrm{mM}$ sodium phosphate buffer,
$\mathrm{pH}$ 7.4) and the mixtures were incubated for $10 \mathrm{~min}$ at room temperature and then centrifuged for $10 \mathrm{~min}$ at $3000 \mathrm{rpm}$ and. The absorbance of supernatant was measured at 540 $\mathrm{nm}$ using UV-spectrophotometer. The percent inhibition of haemolysis was calculated as below

$\%$ inhibition of haemolysis $=100 \mathrm{X}\{(\mathrm{OD} 1-\mathrm{OD} 2) / \mathrm{OD} 1\}$

OD1 = Absorbance of supernatant without extractive, and $\mathrm{OD} 2=$ Absorbance of supernatant with extractive

Heat-induce haemolysis: Aliquots $(5 \mathrm{ml})$ of the isotonic buffer, containing $1.0 \mathrm{mg} / \mathrm{ml}$ of different extracts of the plant were put into two duplicate sets of centrifuge tubes The vehicle, in the same amount, was added to another tube as control. Erythrocyte suspension $(30 \mu \mathrm{L})$ was added to each tube and mixed gently by inversion. One pair of the tubes was incubated at $54{ }^{\circ} \mathrm{C}$ for $20 \mathrm{~min}$ in a water bath. The other pair was maintained at $0-5^{\circ} \mathrm{C}$ in an ice bath. The reaction mixture was centrifuged for $3 \mathrm{~min}$ at $1300 \mathrm{~g}$ and the absorbance of the supernatant was measured at $540 \mathrm{~nm}$ using UV spectrometer. The percentage inhibition or acceleration of hemolysis in tests and was calculated using the following equation:

$\%$ inhibition of hemolysis $=100 \times\{(\mathrm{OD} 2-\mathrm{OD} 1) /(\mathrm{OD} 3-\mathrm{OD} 1)$

Where, OD1 = test sample unheated, OD2 = test sample heated and, OD3 = control sample heated

\subsection{Statistical analysis}

The data were expressed as Mean \pm SEM. The statistical analysis was carried out using t-test. A p value $\leq 0.05$ was considered as statistically significant.

Ethical approval: Ethical consent was taken from the institute for this experiment (1103MS 101)

\section{Acknowledgement}

This research was supported by a grant (BS-142/2012) to MSH from the Ministry of National Science and Technology, Government of the people's republic of Bangladesh.

\section{Authorship statement}

Concept - MSH, Design-SKA, MSH, Supervision-MSH, Resources - MSH, Materials-MSH, Data collection/ processing-SKA, Analysis/interpretation - SKA, MIHK, MMB, Literature Search-SKA, MIHK, MMB, Manuscript writing-SKA, MIHK, MSH, Critical review - SKA, MIHK, $\mathrm{MMB}, \mathrm{MSH}$

\section{Conflict of Interest}

None 


\section{REFERENCE}

[1] Ghani A. Medicinal Plants of Bangladesh: Chemical Constituents and Uses. Asiatic Society of Bangladesh, Dhaka, Bangladesh, 1998

[2] Babu PD, Subhasree RS. Antimicrobial activities of Lawsonia inermis: A review. Acad J Plant Sci. 2009; 2: 231-232.

[3] Sujatha S. Complementary and alternative therapies in palliative care: A transition from modern medicine to traditional medicine in India. J Canc Pain Sym Pall. 2005;1: 25-29.

[4] Khan MA, Marwat KB, Gul B, Wahid F, Khan H, Hashim S. Pistia stratiotes. (araceae): phytochemistry, use in medicines, phytoremediation, biogas and management options. Pak J Bot. 2014; 46(3):851-860.

[5] Wang Y and Lobstein T. Worldwide trends in childhood over - weight and obesity. Int J Pediatr Obes. 2006; 1(1):11-25.

[6] Jong WY. Possible anti-obesity therapeutics from nature - A review. Phytochemistry. 2010;71: 1625-41.

[7] Chowdhury JA, Islam MS, Asifuzzaman SK, Islam MK. Antibacterial and cytotoxic activity screening of leaf extracts of Vitex negundo (Fam: Verbenaceae). J Pharm Sci Res. 2009;1: 103-108.

[8] Pennachio M, Jefferson L, Havens K. Uses and Abuses of PlantDerived Smoke: Its Ethnobotany as Hallucinogen, Perfume, Incense, and Medicine, 1st Ed, Oxford University Press, New York, USA, 2010

[9] Jain SK, Borthakur SK. Solanaceae in Indian tradition, folklore, and medicine. In: D’Arcy WG, Solanaceae: Biology and Systematics, Colombia University Press, New York, 1986

[10] 1Ezeugwu CO, Okonta JM, Nwodo NJ. Antidiabetic properties of ethanolic fruit extract of Solanum aethiopicum L. Res J Pharmaceut Allied Sci. 2004;2(2):251-254.

[11] Anosike CA., Abonyi O., Ubaka CM. Does the African garden egg offer protection against experimentally induced ulcers? Asian Pac J Trop Med. 2011;4(2):163-166.

[12] Buettner R, lmerich JS, Bollheimer LC. High-fat diets: modeling the metabolic disorders of human obesity in rodents. Obesity. 2007;15(4):798-808.

[13] 1Gajda AM. High fat diets for diet-induced obesity models. Open diet purified formula for rats. Obesity. 9 pages, 2009.

[14] Anon. Pravastatin, simvastatin, and lovastatin for lowering serum cholesterol concentrations. Med Lett Drugs Ther. 1992;34:57-58.

[15] Birari RB, Bhutani KK. Pancreatic lipase inhibitors from natural sources: unexplored potential. Drug Discov Today. 2007;12:879-889.

[16] Ballinger A, Peikin SR. Orlistat: its current status as an antiobesity drug. Eur J Pharmacol. 2002; 440:109-117.

[17] Han LK, Takaku T, Li J, Kimura Y, Okuda H. Anti-obesity action of oolong tea.Int J Obes Relat Metab Disord. 1999; 23:98-105.

[18] Lin JK, Lin-Shiau SY. Mechanisms of hypolipidemic and antiobesity effects of tea and tea polyphenols. Mol Nutr Food Res. 2006; 50:211-217.

[19] Nakai M, Fukui Y, Asami S, Toyoda-Ono Y, Iwashita T, Shibata $\mathrm{H}$, Mitsunaga T, Hashimoto F, Kiso Y. Inhibitory effects of oolong tea polyphenols on pancreatic lipase in vitro. J Agric Food Chem 2005; 53(11):4593-4598.

[20] Thielecke F, Boschmann M. The potential role of green tea catechins in the prevention of the metabolic syndrome - a review. Phytochemistry. 2009;70:11-24.

[21] Hwang JT, Park IJ, Shin JI, Lee YK, Baik HW, Ha J, Park OJ. Ganistein ECGC and capsaicin inhibit adipicyte differentiation process via activating AMP - activated protein kinase. Biochem Biophys Res Commun. 2005;338(2):694-69.

[22] Lin J, Della-Fera MA, Baile CA. Green tea polyphenol epigallocatechin gallate inhibits adipogenesis and induces apoptosis in 3T3-L1 adipocytes. Obes Res. 2005;1386):982-990.

[23] Hsu CL, Yen GC. Phenolic compounds: evidence for inhibitory effects against obesity and their underlying molecular signaling mechanisms. Mol Nutr Food Res. 2008;52(1):53-61

[24] Raju GS, Moghal MMR, Dewan SMR, Amin MN, Billah MM. Characterization of phytoconstituents and evaluation of total phenolic content, anthelmintic, and antimicrobial activities of Solanum violaceum Ortega. Avicenna J Phytomed. 2013; 3(4):313-320.

[25] Stein PD, Beemath A, Olson RE. Obesity as a risk factor in venous thromboembolism. Am J Med. 2005; 118(9):978-980.

[26] Nicolini FA, Nichols WW, Mehta JL, Saldeen TGP, Schofield R, Ross M, Player DW, Pohl GB, Mattsson C. Sustained reflow in dogs with coronary thrombosis with $\mathrm{K} 2 \mathrm{P}$, a novel mutant of tissue plasminogen activator. J Am Coll Cardiol. 1992; 20(1):228-235.

[27] 2Marder VJ. Recombinant streptokinase - opportunity for an improved agent. Blood Coagul Fibrinolysis. 1993;4: 1039-1040.

[28] Wu DH, Shi GY, Chuang WJ, Hsu JM, Young KC, Chang CW, Wu HL. Coiled coil region of streptokinase gamma-domain is essential for plasminogen activation. J Biol Chem. 2001;276 (18): 15025-15033.

[29] Hossain MS, Chowdhury AA, Rahman MS, Nishimura K, Jisaka M, Nagaya T, Shono F, Yokota K. Development of enzyme-linked immunosorbent assay for D12-prostaglandin $\mathrm{J} 2$ and its application to the measurement of the endogenous product generated by cultured adipocytes during the maturation phase. Prostaglandins Other Lipid Mediat. 2011; 94:73-80.

[30] Shinde UA, Phadke AS, Nair AM, Mungantiwar AA, Dikshit VJ, Saraf MN. Membrane stabilizing activity - a possible mechanism of action for the anti-inflammatory activity of Cedrus deodara wood oil. Fitoterapia. 1989; 70: 251-257.

[31] Omale J, Okafor PN. Comparative antioxidant capacity, membrane stabilization, polyphenol composition and cytotoxicity of the leaf and stem of Cissus multistriata. Afr J Biotechnol. 2008; 7: 3129-3133.

[32] Anosike CA, Obidoa O, Ezeanyika LUS. Membrane stabilization as a mechanism of the anti-inflammatory activity of methanol extract of garden egg (Solanum arthiopicum) Daru J Pharm Sci. 2012; 20(1):76.

[33] Singleton VL, Rossi JA. Colorimetry of total phenolic with phosphomolybdicphosphotungstic acid reagent. Am J Enol Viticult. 1965;16: 144-158. 
[34] Kim DO, Jeong SW, Lee CY. Antioxidant capacity of phenolic phytochemicals from various cultivars of plums. Food Chem. 2003; 81:321-326.

[35] Allian CC, Poon LS, Chan CS, Richmond W, Fu PC. Enzymatic determination of total serum cholesterol. Clin. Chem. 1974; 20(4):470-475.
[36] Bucolo G, David H. Quantitative determination of serum triglycerides by the use of enzymes. Clin Chem. 1973;19(5):476-482.

[37] Prasad S, Kashyap RS, Deopujari JY, Purohit HJ, Taori GM, Daginawala HF. Effect of Fagonia Arabica (Dhamasa) on in vitro thrombolysis. BMC Complement Alternat Med. 2007;7:36. 